\title{
A AVALIAÇÃO NA EDUCAÇÃO BÁSICA: AMPLIANDO A DISCUSSĀO
}

\author{
Léa Depresbiteris \\ Doutora em Educação pela Universidade de São Paulo - USP
}

\section{Resumo}

Este texto busca estimular a reflexão sobre a avaliação no contexto do ensino básico, destacando a intrínseca relação entre as dimensठ̋es quantitativa e qualitativa e a necessidade da construção de um quadro referencial de análise. Discute-se que, um dos pressupostos mais importantes desse quadro é o de uma avaliação criterial, cujo potencial é nos colocar mais distantes da idéia de classificaçăo entre escolas. Outro aspecto que o texto apresenta é o da possibilidade de o ensino privado também realizar a avaliação de suas ações, de modo a repensar, juntamente com os demais sistemas nacionais de avaliação, a qualidade o ensino básico.

Palavras-chave: Avaliação, educação básica, ensino público, ensino privado, qualidade da educação, avaliação interna, avaliação externa.

\section{Resumen}

Este texto estimula la reflexión sobre la evaluación en el contexto de la enseñanza básica, destacando la intrínseca relación entre las dimensiones cuantitativa y cualitativa y la necesidad de la elaboración de un cuadro referencial de análisis. Se discute que uno de los presupuestos más importantes de ese cuadro es el de una evaluación del criterio utilizado, que puede potencialmente distanciarnos de la idea de clasificación entre las escuelas. Otro aspecto que el texto presenta es el de la posibilidad de que la enseñanza privada también realice la evaluación de sus acciones, para repensar juntamente con los demás sistemas nacionales de evaluación, la calidad de la enseñanza básica.

Palabras-clave: Evaluación; educación básica; enseñanza pública; enseñanza privada; calidad de la educación; evaluación interna; evaluación externa.

\begin{abstract}
The present text aims to encourage a reflection about evaluation in the context of elementary education, highlighting the intrinsic relation between its quantitative and qualitative dimensions and the need to build a referencial frame of analysis as well. It argues that one of the most important presuppositions about this frame is that of a criterion evaluation, which can potentially distance us from the idea of classification among schools. Another point the text introduces is the possibility of private education also evaluating its actions, so that it can, together with other national evaluation systems, reconsider the quality of elementary education.

Keywords: Evaluation, elementary education, public education, private education, education quality, internal evaluation, external evaluation.
\end{abstract}




\section{A avaliação de sistemas educacionais}

Os sistemas nacionais de avaliação, criados desde há algum tempo em muitos países, entre os quais o Brasil, têm certamente potencial para esclarecer os diversos setores da sociedade sobre as tendências da educação. Eles foram criados para estimular a assunção de responsabilidades e a visibilidade que devem ter os sistemas educativos na informação dos diversos atores, em nível individual, institucional, governamental e no conjunto da sociedade.

A questão da avaliação, porém, não é simples. Pelo papel que desempenha no julgamento de valor dos programas e sistemas, a avaliação tem grande poder e, por isso, a importância de uma reflexão aprofundada sobre os diferentes aspectos que a permeiam. Não se pode negar que a avaliação tem força para transformar, justificar ou até desacreditar aquilo que avalia.

No caso dos sistemas educacionais, entre os múltiplos fatores que influenciam a avaliação, dois se destacam: a autonomia da escola de um lado e a responsabilidade do Estado de outro. $O$ Estado não pode restringir a autonomia das escolas, mas é imperioso que ele se responsabilize pela qualidade de seus sistemas educativos, nas esferas pública e privada.

\section{A avaliação no contexto do ensino público e privado}

Na esfera pública, a Secretaria de Educação do Estado de São Paulo já possui um sistema de avaliação do rendimento escolar SARESP - com foco no ensino fundamental e médio. Trata-se de uma iniciativa importante, na perspectiva de uma avaliação sistemática da rede de escolas do Estado.

Por essa iniciativa, esse sistema subsidia desde os gestores das políticas públicas em educação até a sociedade, envolvendo equipes escolares, diretores, coordenadores, professores, alunos e respectivas famílias

Na esfera privada da educação básica que, no Estado de São Paulo, abrange aproximadamente seiscentas escolas, também se faz necessária essa sistematização. A avaliação deveria tornar públicos os resultados da rede privada de ensino, não somente quanto à responsabilidade de cada escola prestar contas da qualidade da 
educação que oferece, como também para o enriquecimento da reflexão do sistema educacional em toda sua plenitude.

A idéia é a de que a avaliação pode funcionar como um excelente fio condutor e integrador das esferas pública e privada, abarcando sistematicamente as múltiplas dimensöes, desde as de natureza essencialmente pedagógica até as variáveis mais abrangentes de natureza institucional.

O ponto fulcral da avaliação dos sistemas é a qualidade da educação. 0 problema é que quando se fala em qualidade vislumbra-se um amplo espectro de fatores, alguns mais explícitos em termos de critérios e indicadores, outros mais implícitos e, conseqüentemente, mais diff́ceis de serem mensurados. Assim, em primeiro lugar, é preciso fazer acontecer um exercício conceitual sobre a natureza da qualidade e de sua aplicação no campo educacional. Em outra esfera de reflexão, é fundamental verificar quais os elementos mais relevantes, valorizar esses elementos, atribuindo pesos a cada um deles. A estimativa de qualidade é complexa e se encontra carregada de valores, não existindo uma medida unidimensional da mesma

A reflexão encaminha também para a idéia de que a medida da qualidade em educaçăo não deve ficar limitada à análise dos desempenhos dos educandos, refletidos, na maioria das vezes, em dados numéricos ou conceituais e não na descrição das habilidades que estão sendo desenvolvidas. Na verdade, é necessário tecer a trama de variáveis que caracterizam esses resultados e lhes dão significado.

É patente que os resultados alcançados em termos do rendimento dos alunos se constituem num ponto de partida importante para a análise dos desempenhos de uma escola, mas é necessário, também, que a esses resultados sejam agregados outros indicadores descritivos de qualidade.

\section{A analise do contexto - dimensões de realidade e temporalidade}

É fundamental que, antes de qualquer decisão sobre a avaliação da qualidade da educação, deva ocorrer uma análise do contexto em que o processo educacional se desenvolve, configurado não só na realidade do momento, mas na sua temporalidade. Essa análise histórica é de fundamental importância para a definição de critérios e indicadores de avaliação. 
Agregando complexidade a essa definição, tem-se que pensar que a avaliação da qualidade da educação deve englobar critérios e indicadores numéricos (quantitativos) e descritivos (qualitativos), uma vez que quantidade e qualidade estão estreitamente relacionadas.

A expansão da rede de escolas privadas merece ser considerada pelo sistema e seus usuários. Essas escolas devem ser analisadas pela população que as procuram na busca de maior qualidade de educação para os filhos e pelo próprio sistema educacional em que estão inseridas. Assim, apesar da variedade em termos de significados, deve haver uma reflexão sobre uma série de atributos ou elementos descritores no sentido de responder a algumas questões, como por exemplo: 0 que deve ser considerado como qualidade de educação? 0 que significa qualidade do ensino privado? Quais os fatores impulsores e restritivos dessa qualidade? Em que medida ela está se efetivando na maioria dos estabelecimentos do sistema? Quais as responsabilidades das varias instâncias de decisão do sistema?

Avaliar um sistema educativo repousa na idéia de que uma escola é muito mais do que uma simples junção de classes. A escola existe em um certo contexto e é fundamental que este seja analisado, uma vez que se constitui em fator determinante para a qualidade de ensino.

\section{A avaliação e a escola como realidade complexa}

A avaliação precisa ser capaz de reconhecer as escolas como organizaçōes complexas que devem ser focalizadas analiticamente para além dos limites restritos do espaço pedagógico.

Assim, paralelamente à necessidade de se compreender as especificidade dos estabelecimentos de ensino, é preciso situar a análise dos resultados num contexto mais amplo, no qual a educação está se desenvolvendo.

É fundamental a distinção entre avaliar a política educativa e avaliar o que acontece na escola. Embora em diferentes níveis de abrangência, a avaliação da escola e a avaliação do sistema não são estanques, elas apresentam forte interrelação.

Isso reforça a necessidade da avaliação ser realizada em dois níveis: micro, relacionado a cada estabelecimento de ensino, o que deve ser pautado pela noção de especificidade de cada contexto e 
macro, ou seja, uma avaliação do sistema, o que imprime a ela um caráter de generalidade.

Outra discussão é sobre as dimensões interna e externa que deveriam caracterizar a avaliação de cada estabelecimento de ensino.

A avaliação interna de cada escola do ensino privado está diretamente relacionada às formas de sua gestão educativa e ao seu projeto pedagógico, harmonizado com as diretrizes da educação. Isso significa que os estabelecimentos escolares não são inteiramente específicos, particulares, únicos, o que obriga ao próprio sistema educativo em que estão inseridos a refletirem sobre critérios mais amplos de qualidade.

Desta maneira, na dimensão interna, a avaliação deve alimentar a reflexão da própria escola, ou seja de sua comunidade, sobre as formas de sua gestão educativa e sobre seus propósitos e resultados, representados no seu projeto pedagógico. Uma das formas de processar essa análise interna poderia ser a da auto-avaliação. 0 pressuposto é o de que antes de criticar, deve-se praticar a auto-crítica. Contudo, essa é apenas uma alternativa; a própria escola deveria criar suas metodologias de avaliação, sempre considerando que não existe uma única metodologia capaz de medir e garantir a qualidade de ensino do aprendiz.

O importante é que a escola realize, além de uma avaliação interna, uma avaliação externa para que possa ser considerada de qualidade no conjunto do sistema e não apenas intra-muros.

A avaliação de cada escola baseada na dupla perspectiva interna e externa - pode proporcionar a criação de uma cultura avaliativa e pode propiciar o alcance de alguns objetivos básicos: processo de contínuo aperfeiçoamento de sua missão de educar, instrumento de gestão educativa, elemento importante de informação para políticas públicas, e prestação de conta aos educandos e seus familiares.

O desafio é buscar o equilíbrio entre a avaliação interna representada pela reflexão dos atores sobre suas práticas e a avaliação externa na perspectiva do desejo de transparência das ações e no fomento de um debate sobre o sistema.

Uma avaliação exclusivamente interna pode impedir a escola de situar-se criticamente nos desempenhos do sistema de ensino.

Uma avaliação de caráter apenas externo, por outro lado, pode ressaltar meramente um espírito de competição entre escolas, e 
tornar-se nefasta ao assumir um enfoque de concorrência. Cumpre ressaltar que a avaliação que exacerba a classificação pode deturpar fins educacionais.

É evidente que sempre haverá uma certa diferenciação entre as escolas; a uniformidade é totalitarismo. Embora diferentes, contudo, é preciso que tenham um eixo norteador que não prejudique a qualidade da formaçăo dos educandos.

\section{A avaliação da aprendizagem e os padrões mínimos de qualidade}

A definição de padrões mínimos de qualidade é um desafio para a avaliação. Especificamente quanto à avaliação da aprendizagem dos educandos, os critérios e indicadores devem se relacionar diretamente aos resultados obtidos em termos dos graus de domínio de competências, capacidades ou habilidades, na perspectiva de uma educação vista não exclusivamente como pragmática.

Outro aspecto importante é o da avaliação de acompanhamento dos educandos. É a fase de transição entre o interno da escola e a sociedade. A idéia é a de que a qualidade de uma escola também precisa agregar a seus resultados internos as peculiaridades e variáveis especifficas de cada aluno que a deixa, quer seja na evasão ao longo do processo, quer seja ao final da formação.

Isso implica avaliação formativa, mesmo que sejam necessários alguns cortes no processo, de modo a que se possam obter dados para uma análise na amplitude do sistema educacional privado e público. 0 caráter formativo diz respeito à orientação constante na melhoria das ações em nível institucional, curricular e de cada educando.

Em termos mais específicos do processo de ensino $e$ aprendizagem, apesar de a prática avaliativa ser familiar aos docentes, deve-se estimulá-los para que compreendam os motivos da avaliação em dimensão mais ampla. Essa compreensão levará à melhoria da aprendizagem e da avaliação dos alunos. Isso implica capacitação precedida e acompanhada por sensibilização constante

Reforçando a questão da temporalidade, a escola deverá avaliar suas açöes numa perspectiva de presente, passado e futuro. Isso caracteriza o aspecto longitudinal dos estudos, tendo como alvo o resgate dos fatos que configuram a história de vida de cada escola. 


\section{A integração entre o sistema público e o sistema privado}

Operacionalmente, o sistema de avaliação do ensino privado poderia se iniciar com um projeto, pelo qual escolas privadas comporiam uma amostra da sua população. Evidentemente, alguns critérios deveriam nortear a composição dessa amostra. Um desses critérios é o da representatividade, outro o da estratificação. $O$ critério de estratificação deve garantir que a análise dos resultados possa ser feita no contexto regional, com respeito aos aspectos culturais. Antes de propor uma integração entre os sistemas público e privado deve haver uma análise aprofundada da adequação de ambas as partes.

Importante, também, que haja clareza sobre os objetos de avaliação. Para isso, talvez seja necessário definir algumas dimensões, por exemplo, dimensão humana (ou de pessoal), de ensino, aprendizagem e orientação dos educandos (o que exige a análise de alguns componentes essenciais do processo, como: abordagens educativas, objetivos, conteúdos, metodologias, estratégias, abordagens e formas de avaliação) e material (ou física).

Contextualizam essa análise indicadores relacionados à política educacional, às condições de infra-estrutura do sistema e das escolas, à gestão e à infra-estrutura de cada escola, à qualidade de seu projeto pedagógico, à capacitação dos docentes, ao clima escolar, entre outros.

\section{A avaliação por comparação absoluta, mais do que relativa}

Não se pode desconsiderar que a responsabilidade de qualquer escola é oferecer boa educação. Tanto para a avaliação interna quanto externa é imprescindível a definição de objetivos, critérios e indicadores de avaliação. Há que se ressaltar o desafio dessa empreitada. Toma-se como pressuposto a existência de diferentes níveis de valoração sobre o que cada escola produz, dependendo de quem analisa os resultados.

Para que essa avaliação possa ser bem fundamentada, cada escola deveria se pautar por um quadro referencial de critérios que permita inferências sobre qual a qualidade educacional desejada. A esse quadro específico, devem estar agregados critérios mais amplos de natureza do sistema, não só do sistema privado, foco desse documento, como do sistema educacional na interdependência de seus níveis: infantil, educação básica e educação superior. 
A meta é a de que avaliação das escolas no sistema privado chegue a um acordo sobre os principais aspectos conceituais e, no mínimo, sobre critérios e indicadores mensuráveis (numericamente ou descritivamente) com relação à qualidade. Isso caracteriza a idéia de avaliação por critérios absolutos, cuja lógica é a comparação de cada escola com padrões de qualidade educacional pré-estabelecidos. Desta maneira, os quadros referenciais de análise devem estar explicitados no sistema e na escola.

Há que se ressaltar que a construção desses quadros de referência exige um cenário de fundo de natureza teórica e interpretativa. Serăo diferentes os critérios que visem à uma aprendizagem voltada apenas para o domínio de conteúdos escolares, de outra que além desses conteúdos invista no desenvolvimento de uma aprendizagem mais crítica. Além disso, é preciso advertir que a presença desses quadros referenciais não exclui a dificuldade da análise e da interpretação dos resultados, uma vez que estes nunca esgotarão a realidade.

Numa visão ainda mais ampla, a avaliação com base em critérios absolutos deve ser estabelecida em consonância com os critérios de outros sistemas de ensino. Para realizar essa articulação, reforça-se novamente que a avaliação deve ser ao mesmo tempo quantitativa e qualitativa sem que essas duas facetas sejam analisadas de forma dicotômica.

Em síntese, três propósitos centrais devem nortear uma avaliação: fornecer resultados para a gestão da educação, subsidiar a melhoria dos projetos pedagógicos das escolas e propiciar informaçōes para a melhoria da própria avaliação, o que se caracteriza como meta-avaliação.

O sistema avaliativo deve ser provocador de ações de melhoria, caso contrário poderá se transformar em mero instrumento de coleta de dados.

Os objetivos da avaliação visariam então:

- alimentar a reflexão de cada escola sobre os processos e produtos de seu projeto pedagógico e de sua gestão educativa;

; incentivar uma cultura avaliativa nos sistemas educativos, nas escolas e nos próprios sistemas de avaliação.

- fomentar a reflexão e revisão das políticas educacionais, pela possibilidade de análise dos desempenhos dos diversos sistemas educativos do país. 


\section{Algumas considerações gerais de caráter orientador da}

discussão sobre o tema

Com a finalidade de subsidiar as reflexões, alguns aspectos devem ser aqui apontados:

- A avaliação do sistema privado deve tornar públicos seus resultados, na busca de maior transparência e de definição de responsabilidades.

- A avaliação do sistema do ensino privado deve estar configurada no contexto dos sistemas educativos.

- Antes de qualquer decisão avaliativa, é fundamental considerar a realidade na qual o processo educacional se desenvolve.

- Além da dimensão de realidade, é importante refletir sobre a temporalidade do processo educativo, para que os critérios possam ser definidos em termos comparativos absolutos, mais do que em termos de comparação relativa (comparação entre escolas).

- A avaliação da qualidade da educação deve englobar critérios e indicadores numéricos (quantitativos) e descritivos (qualitativos), uma vez que quantidade e qualidade estão estreitamente relacionadas.

* A integração entre a avaliação do sistema público e privado deve ser analisado em termos de racionalização de recursos, na busca de parceria real de contrapartida de um sistema e de outro.

- A avaliação deve considerar dois níveis: macro do sistema e micro de cada estabelecimento.

- Em cada estabelecimento de ensino é fundamental aliar a avaliação interna com a avaliação externa. A avaliação interna de cada escola do ensino privado está diretamente relacionada às formas de sua gestão educativa e ao seu projeto pedagógico. A avaliação externa exige uma análise de impactos no sistema educativo e no sistema social mais amplos.

- Antes de ser ampliado, o processo avaliativo deveria ser realizado numa dimensão mais delimitada, com amostras de escolas estratificadamente representativas.

- A avaliação da aprendizagem pode se constituir num ponto de partida da avaliação curricular e institucional, mas nunca o único indicador.

- Para que a avaliação se caracterize como orientadora das ações educativas, é importante que os resultados sejam usados para 
levantamento de hipóteses sobre possíveis causas de problemas, subsidiando análises mais aprofundadas e nunca como forma de punição dos estabelecimentos e dos elementos humanos que o constituem.

; Ao professor deve ser dada capacitação para que a avaliação da aprendizagem ressalte seu aspecto formativo de melhoria dos desempenhos dos educandos.

- Uma cultura avaliativa sadia depende da saúde de todas as instâncias que realizam a avaliação.

- Depois de realizada a avaliação, é de responsabilidade do sistema o gerenciamento das necessidades de melhoria detectadas. 